\title{
ETIMOLOGÍA ÁRABE DEL CID, COMO ANTROPÓNIMO («EL LEÓN») Y COMO TOPÓNIMO («EL SEÑOR Y/O GOBERNADOR ALMOHADE»)
}

Por

MÍKEL DE EPALZA

La etimología árabe del nombre propio Cid, antropónimo y topónimo, es generalmente conocida: ambos nombres vendrian, directa o indirectamente del árabe sayyid, con significado de «señor».

Pero se puede probar, aunque sea con algunas incertidumbres propias de la falta de documentación directa de esa evolución, que se puede remontar a una etapa anterior, en ese origen etimológico de los conocidos Cid, en árabe.

En efecto, el antropónimo Cid, antes de ser «el señor» 0 «mi señor» de los cantares castellanos, sería el título militar «El León», en versión árabe dialectal del también título militar de «El Campeador».

El topónimo, por su parte, se refiere algunas veces no al héroe castellano, sino a un «señor» o propietario local, especialmente a un «gobernador-príncipe» almohade, que se puede personalizar en algún caso con cierta probabilidad en el sáyyid Abu-Zaid, el penúltimo soberano musulmán de Valencia, a principios del siglo XIII.

El nombre del Cid es suficientemente importante, en la cultura hispánica y universal, como para justificar cualquier investigación científica novedosa sobre su origen. Por otra parte, las denominaciones locales referidas al Cid se atribuyen siempre a ese famoso personaje, cuando tienen, a veces, otro origen histórico. Esta nota de onomástica árabe-hispánica pretende aportar algo más de luz en ambos temas.

El antropónimo Cid: primero «León», luego «Señor»

El Cid es uno de los tres grandes personajes literarios que la cultura hispánica 
ha dado a la literatura universal, con Don Quijote y Don Juan (1). Pero, de los tres, es el único que fue además un personaje histórico relevante, Rodrigo Díaz de Vivar, en la compleja situación socio-política del último tercio del siglo XI en la Península Ibérica, Al-Andalus de los árabes, con un papel militar que le valió el titulo de Campeador, recogido explicitamente por fuentes escritas en árabe, en latín y en romance.

La etimología árabe de este antropónimo, Cid, no ha ofrecido ninguna dificultad: vendría de sayyid, "señor», pronunciado popularmente sid, y de sayyid-î, «mi señor», pronunciado sidî en árabe coloquial.

Esta etimología es evidente en la literatura hispana y para los que la estudian. Pero hay que advertir que ese nombre o título de Rodrigo no aparece en ningún texto árabe, hasta época moderna (2). Hace ya unos años, había emitido yo la hipótesis de que, más allá de la etimología conocida ya por el autor del Cantar, se podía remontar a un epíteto militar árabe, atribuido por los contemporáneos árabehablantes de Rodrigo, que «traduciría» el romance «Campeador»: As-Sid, «El León», o simplemente Síd, «León». En un trabajo de 1974 (3) mostraba diversas convergencias, lingüísticas, sociológicas y literarias, para apoyar dicha hipótesis.

Ahora creo poder aportar una prueba importante en favor de esa etimología del antropónimo Cid, además de la argumentación aportada en aquella publicación, que se vuelve a publicar en este trabajo, como apéndice, ya que aquel planteamiento parece enteramente válido y reforzado, quince años después, por esta nueva prueba (4).

La argumentación nacia de las dificultades, advertidas también por el profesor egipcio Ahmad Tahar Makki -traductor al árabe del Poema del Mio Cid - para admitir el uso por los árabes del epíteto sáyyid, "señor», ante el nombre de Rodrigo. El epíteto sáyyid se utiliza muy habitualmente como tratamiento en vocativo, dirigiéndose a una persona cualquiera, especialmente en la lengua hablada. Pero se reserva como título a personajes venerables del Islam, como autoridades políticas y espirituales. Podia por tanto haberse utilizado al dirigirse a Rodrigo, pero era extraño que se le reconociese habitualmente, en forma de título, una autoridad política y espiritual en ambiente islámico.

Mi planteamiento aportaba - positivamente, y no ya como argumento negativovarios hechos más: la necesidad de buscar a Rodrigo un título militar correspondiente al de Campeador (utilizado por las crónicas árabes, pero muy poco eufónico para un contexto militar y hasta literario, en árabe); el valor militar y épico de la imagen

(1) Ver M. DE EPALZA - S. GUELLOUZ: Le Cid, personnage historique et litteraire. Anthologie de textes arabes, espagnols, français et latins avec traductions, Paris, 1983.

(2) Ver la traducción árabe del Cantar por A.T. MAKKI: Malhamat as-Sió, Cairo, 1970, que expone algunas reflexiones paralelas a las que aquí se presentan, sobre el origen del nombre del Cid, en árabe.

(3) Presentado en el Congreso de la Asociación Internacional de Hispanistas, en Burdeos, fue publicado luego por M. DE EPALZA: «El Cid = El León: ¿epíteto árabe del Campeador?», Hispanic Review, Philadelphia, 45/1, 1977, 67-75, reproducido como apéndice de este artículo en el actual número 7 (1990), pp. $227-236$ de la revista Sharq Al-Andalus. Estudios Arabes, Alicante.

(4) Agradezco a la Dra. M.J. Rubiera Mata el que me proporcionara esta documentación que confirmaba mi hipótesis de 1974 
del león (síd o cid, en árabe dialectal (5)); y, sobre todo, la importancia de la lucha entre el Cid y un león, en el Cantar, que tiene un valor simbólico, quizás con fundamento onomástico, basado en la similitud de una imagen «leonina», como recogió el Romancero, en versión más amplia que el verso «a maravilla lo han quantos que i son» (Cantar, 2302):

\author{
Aturdido está el gentío \\ Viendo lo tal, no catando \\ Que ambos eran leones, \\ Mas el Cid era el más bravo (6)
}

Muestra de la fuerza «viril» de la imagen del síd - «león» en la lengua y la literatura magrebíes-, aun hoy en día, sería el texto popular tunecino que desea para el niño recién nacido la fuerza y la astucia del león, su éxito social (7):

Que mi hijo sea un León / Señor (síd).

Que mi hija esté viva / sea Serpiente (hayya).

También se recogía en aquella publicación algo de la abundante bibliografía sobre el sentido valeroso del «león», a la que podría añadirse un romance judío marroquí, en el que se trastuecan todos los personajes valerosos, pero quizás con un trasfondo de Sidi-León (8):

\author{
Delante del rey León \\ Ximena salió una tard, \\ demandando iba justicia. \\ ... \\ Haremos un gran concierto, \\ Ximena, si a ti te place, \\ de casarte con el Sidi \\ sabiendo que tanto vale. \\ Alegre salió Ximena \\ de los palacios reales, \\ de casarse con el Sidi \\ sabiendo que tanto vale.
}

Pero es el episodio del león, al principio de la tercera parte del cantar, el elemento principal que hasta ahora se podia aducir documentalmente sobre la relación Cid-león, relación que se expresa sintéticamente en versos posteriores (2718-2719, 2762):

(5) El león como animal ha dado numerosos nombres de varón en árabe, recogidos y estudiados por A. SCHIMMEL: Islamic Names, Edinburgh, 1989, pp. 2 y 14. En Oriente Medio, en los siglos XI y Xil contemporáneos del Cid hispánico, se llamaban también «León» (en turco Arslan) varios príncipes militares turcos selyuquíes y (en kurdo Shiriuh) el conquistador kurdo de Egipto, tío de Saladino. Francisco Franco Sánchez me señala unos hechos maraviliosos relacionados con un león dominado por el primer soberano almohade, de mediados del siglo XII, según un texto comentado por A. HUICl: «La leyenda y la historia en los origenes del imperio almohade», Al-Anda/us, 14, 1949, 367-368. Son datos para situar la creación de ese epiteto militar leonino no sólo en el ambiente de la épica europea, como se ha estudiado abundantemente, sino en la realidad de la onomástica militar islámica de la época de Rodrigo.

(6) Romancero General, Biblioteca de Autores Españoles, X, 1945, 542-543.

(7) Refrán escogido de un profesor tunecino de la Facultad de Medicina, según L. LABIDI: Cabra Hachma. Sexualité et tradition, Túnez, 1989, p. 19.

(8) A. DE LARREA PALACIN: Romances de Tetuán, Madrid, 1952, referencia que debo a Luis F. Bernabé Pons. 
Hirán aquestos mandados al Çid Campeador; nos vengaremos aquesta por la del león.

La desondra del león assís irá vengando (9)

No se va a presentar aquí de nuevo la amplia bibliografía sobre estudios acerca del león en el Poema de Mio Cid (10). Pero una nueva prueba documental directa de la etimología Cid-León - prueba y no sólo verosimilitud de una hipótesis - la da un texto literario, probablemente en verso árabe en el original desconocido, contemporáneo de la toma de Valencia por Rodrigo. Se trata de la elegía de Al-Wáqqaxi (A/-Waqqasî), conocida por su traducción al castellano con transcripción paralela del árabe (11). Es al mismo tiempo una arenga a los valencianos sitiados por las tropas de Rodrigo.

Este texto de Al-Wáqqaxi plantea muchos problemas en su conjunto, que no se va a estudiar directamente aquí: el de la prioridad o no del texto castellano sobre el árabe transcrito (creemos que un texto árabe precedió a la traducción castellana, y que la transcripción árabe del texto alfonsí es el de una reconstrucción árabe a partir del castellano); el de la factura poética o no del texto (creemos que el texto árabe original estaba en prosa rimada o en verso rayaz); etc. Aunque estos temas inciden en la interpretación que afecta al tema del «león» cidiano, todas las hipótesis presentadas para solventar esos problemas, por muy estructuradas que estén, no son los suficientemente sólidas como para negar dos hechos importantes de la «estrofa» número 16:

a) que se habla de un león amenazando a Valencia,

b) que se sitúa a ese león en un punto cardinal con respecto a esa ciudad.

El texto castellano de la estrofa, según Nykl (al que no sigo en la ordenación métrica), reza así (12):

Si fuer a diestro, matar mâ el aguaducho.

Si fuer a siniestro, matar mâ el león.

Si fuer adelant, morré en la mar.

Si quisiere tornar atrás, quemar mâ el fuego.

Dada la situación de la Valencia sitiada por Rodrigo, angustiada por no poder salir de su situación, los puntos cardinales se sitúan aproximadamente de la forma

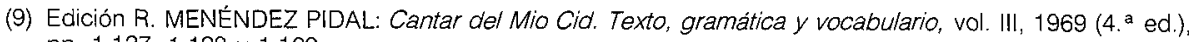
pp. $1.127,1.128$ y 1.129 .

(10) Ver bibliografía sobre el episodio del león con poca relación directa con nuestro tema, en F. MARCOS MARiN: Cantar de Mio Cid. Edición modernizada, estudio y notas, p. 52. Ver, en cambio, interesante estudio de M.V. ORDOÑEZ PALACIOS: «Representación del león en el arte hispanomusulmán», Actas del XXIII Congreso Internacional de Historia del Arte, Granada, 1976, 170-177.

(11) Edición de R. MENÉNDEZ PIDAL: :Sobre Aluacaxi y la elegia árabe de Valenciam, Homenaje a D. Francisco Codera, Zaragoza, 1904, 391-409, sacando el texto castellano y el texto árabe transcrito en caracteres latinos de la Primera Crónica General de España y estudiando ambos textos, con la ayuda del arabista Julián Ribera y Tarragó, quien volveria a publicar las conclusiones de sus trabajos con Menéndez Pidal en la revista El Archivo (t. I, 1887) y en Disertaciones y opúsculos, Madrid, 1928, II, 275-291. Sobre estos textos, ver los importantes estudios de A.R. NYKL: "La elegia árabe de Valencia», Hispanic Review, Philadelphia, 1940, 9-17 y en su Hispano-Arabic Poetry and its Relations with the Old Provençal Troubadour, Baltimore, 1946 (reimpresiones 1970, 1986), 303-309; F. CORRIENTE: «De nuevo sobre la elegia árabe de Valencia», Al-Qantara, Madrid, VIII, 1987, 331-346.

(12) A.R. NYKL: Hispano-Arabic Poetry..., p. 306. 
siguiente, dada la posición - la única aparentemente segura-- del mar, enfrente (13):

Enfrente, el mar (Este)

A la derecha, el aguaducho (Sur)

A la izquierda, el león (Norte)

Detrás, el fuego (Oeste)

Según la hipótesis que se va a intentar justificar, la situación del asedio explica los cuatro elementos del texto literario, que tiene evidente factura estilística cuadrimembre y que se puede glosar de la forma siguiente:
Al Este está el mar, que no permite huir.
Al Sur está la red de acequias y la Albufera, inundadas por mandato del Cid, el «aguaducho".
Al Oeste está el fuego del asedio, desde el arrabal de Rayosa, a la orilla derecha del río Guadalaviar, la misma orilla en la que se ubica la ciudad de Valencia.
Al Norte esta EJ León, El Cid, en la montañita de El Puig o Cebolla (Ŷubayla), en el arrabal de la Alcudia y en La Almunia de Vilanova al otro lado del río, a su orilla izquierda. FIG. 1

Esta clave de lectura es relativamente sencilla, cuando la realidad del texto es bastante más compleja, sin llegar por ello a desvirtuar el eje central de esta argumentación.

Las primeras dificultades nacen de la transcripción árabe del texto, sea ésta al menos un eco del original árabe de donde se sacó el castellano, o sea re-traducción al árabe de la más primitiva traducción al castellano del texto original, que es la hipótesis que nos parece más probable.

En la transcripción árabe se invierten dos posiciones, abiertamente y sin ningún reparo en dejar patente la contradicción flagrante entre el texto castellano y el árabe transcrito: simâl en árabe es «norte e izquierdo» y no "diestro»; yamîn es «sur y derecho" y no siniestro. Hay que escoger. Daremos prioridad al texto castellano sobre la transcripción del árabe, por mayor coherencia global con nuestra hipótesis.

Donde hemos puesto «la red de acequias y la albufera» en realidad el texto castellano pone «aguaducho» (que suele interpretarse como «inundación», pero también como «acueducto», que puede ser cualquier forma de «conducción de agua», según

(13) Prescindimos del hecho de que para la Valencia árabe las tierras de la parte izquierda del rio Guadalaviar eran "orientales", cuando para nosotros serian septentrionales, porque eso no afecta a las orientaciones del texto de Al-Wáqqaxi (ver M. DE EPALZA: "L'ordenació del territori del País Valencià abans de la conquesta, segons Ibn-Al-Abbar (segle XIII)", Sharq Al-Andalus. Estudios Árabes, Alicante, 5, 1986, p. 49). La identificación de bahar como equivalente árabe de mar (a pesar de que pueda tener otros significados en árabe) vendría confirmada por un curioso topónimo «de reconquistan: la Torre d'Alí Bufat. El falso antropónimo musulmán de esta torre sería una mala interpretación de la pronunciación para los catalanohablantes de una torre 'alà-t bahar «hacia el mar», dirección en la que se encuentra efectivamente esa torre de las murallas de Vaiencia, la más oriental. El estudio de las mutaciones fonéticas de esa deformación no corresponde al tema de este trabajo. 


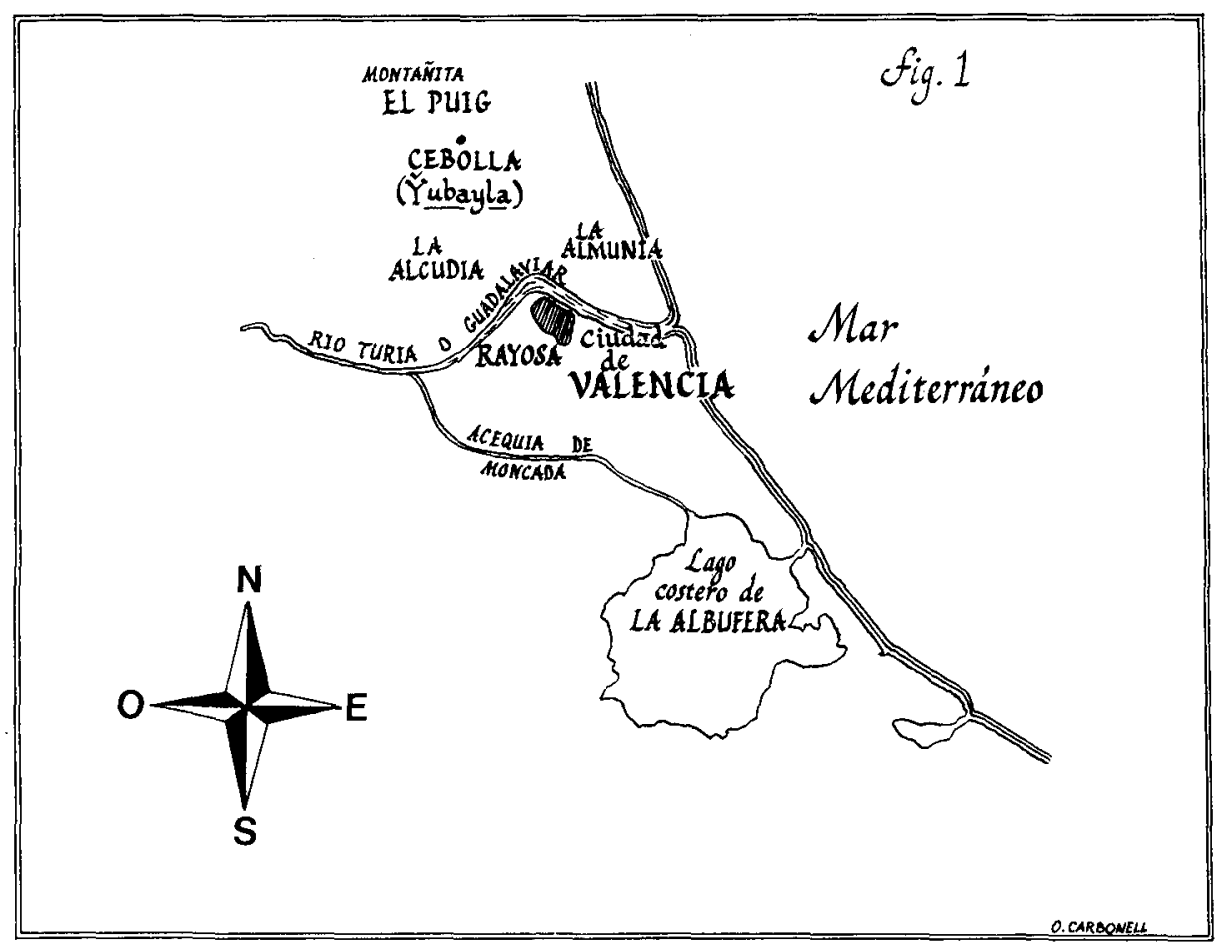

Esquema de la situación de Valencia asediada por El Cid

162 
la etimología latina original, de aguae ductio). La transcripción árabe dice el mi alquitir (al-ma' al-kattir, "la mucha agua»), lo cual también supone una importante divergencia con el texto castellano.

Optamos por creer también que el texto árabe primitivo se acercaba más al sentido de aguaducho. Y hasta se puede precisar más la naturaleza de ese «acueducto», en el sentido de «la red de acequias y la Albufera» de nuestra interpretación, de acuerdo con la estratagema de Rodrigo para evitar la ayuda del ejército almorávide a los valencianos sitiados, haciendo inundar el sistema de acequias de la ribera derecha del río, la meriodinal, de donde podian venir los auxilios militares, desde Xátiva y Alzira.

Partiendo aquí también de la hipótesis de que el texto castellano es más primitivo que la transcripción árabe que se nos ha conservado, se puede intentar remontar de aquél al árabe primitivo, intentando reconstruir su rima, fácilmente detectable, al menos en la estructura cuadrimembre del texto de la «estrofa» 16.

En efecto, los dos últimos miembros de esa estructura cuadrimembre riman en -ru, con sus palabras finales baharu y nâru (bahar y annar, «mar» y «fuego», según la transcripción dialectalizante). Los dos primeros miembros pueden rimar en du,si tenemos al-asadu (allacet de la transcripción del árabe, dialectalizante) o quizás assîdu, «el león», por una parte, y as-saddu («el azud», sustituyendo a el mi alquitir, que ni traduce el aguaducho castellano, ni admite rima).

Se puede por tanto reconstruir la «estrofa» 16 original con la rima siguiente, correspondiente a las cuatro palabras clave de los peligros que amenazan a la Valencia asediada por los cuatro puntos cardinales:

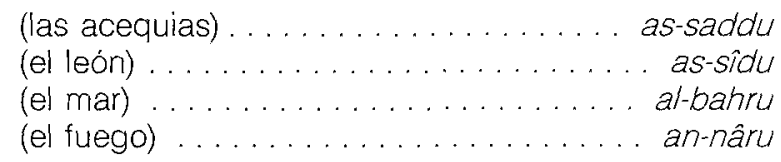

Se puede objetar a esta reconstrucción de la estructura cuadrimembre del texto de la «estrofa» 16 que, sin saber la métrica general del texto de la elegía de Al-Wáqqaxi, es difícil justificar la recreación de la rima del texto árabe original perdido. Pero en realidad ese requisito previo no es necesario: todo texto literario árabe, en prosa o verso, utiliza rimas, y este texto cuadrimembre parece particularmente estructurado, con las cuatro preguntas que se inician igual, correspondientes a los cuatro puntos cardinales y a los cuatro peligros que amenazan a la ciudad. Se puede por tanto admitir esa doble rima en - du y en -ru, que tan bien corresponde al sentido global del texto.

Más aún, sin querer entrar en el problema global de la métrica de todo el texto de Al-Wáqqaxi, me atrevería a afirmar que al menos el fragmento que comentamos refleja perfectamente un posible original poético en metro rayaz, de versos con la misma rima para sus dos hemistiquios, pero diferente de un verso a otro.

Esta opinión difiere de la de Nikl, que quiere reducir el texto original de Al-Wáqqaxi a zéjeles -forzando absolutamente la estructura cuaternaria de la estrofa 16-, y también de la de Corriente, que no halla rastro de métrica poética en la transcripción de este texto árabe dialectalizante. 
Pero habria que suponer, como Ribera y Menéndez Pidal, que la transcripción del texto árabe es de una re-traducción del castellano y no del árabe original de AlWáqqaxi, que sería seguramente en árabe literario o cercano al literario, como corresponde a un alfaquí que se dirige al pueblo en forma parecida a la de la predicación o arenga de la mezquita. Hay que recordar que la rima del rayaz es muy sencilla, cercana a la prosa rimada árabe y a la prosa coránica, y que es género predilecto de la enseñanza y la oratoria. Es, por tanto, muy verosímil que fuera la forma que asumiera el líder religioso Al-Wáqqaxi en su arenga a los valencianos sitiados.

El azud o presa del río, necesario para rimar con el león - que es el importante, semánticamente, porque es el que sitia a Valencia- sería una imagen fiteraria para expresar el conjunto de acequias del sur del río Guadalaviar, que surgen de su ribera derecha a partir de un azud.

Se puede, pues, solventar con bastante probabilidad las divergencias más importantes entre los dos textos (el castellano y la transcripción árabe), dando prioridad al primero y suponiendo, como lo hizo Julián Ribera, que es traducción de un original árabe, mientras que la transcripción del árabe no sería más que una retraducción al árabe vulgar o dialectal de Al-Andalus del texto castellano. Así quedaría confirmada la situación de los cuatro puntos cardinales, con el león al Norte, en los campamentos del Cid sitiador.

Este texto de Al-Wáqqaxi, contemporáneo del sitio de Valencia, menciona, a pesar de sus ambigüedades, dos hechos significativos: 1) El terrible peligro del león para la Valencia sitiada por el Cid, y 2) sitúa a ese león con bastante certeza al Norte de la ciudad. Si la segunda afirmación presenta alguna duda - por las contradicciones de los textos castellano y árabe que nos han llegado, que hemos intentado solventar-, el primer elemento - el peligro del león - nos parece confirmar con un argumento bastante importante la hipótesis de que el Campeador era conocido como Ciđ «León», por los musulmanes contemporáneos suyos.

Como afirmaba en el trabajo precedente, quizás con demasiada modestia, este nuevo paso hacia el conocimiento del origen de ese antropónimo famoso podrá ser confirmado o debilitado por nuevas documentaciones e investigaciones. Pero siempre, «tratándose del título cie uno de los personajes históricos y literarios más importantes de la cultura hispánica, toda investigación, por nimia que sea, puede estar justificadas (14).

\section{El Cid, topónimo con significado de «señor» y/o "gobernador» almohade}

El Cid, personaje relevante de la historia de España, ha dado su nombre, evidentemente, a algunos topónimos: Valencia del Cid (para distinguirla de otras valencias hispánicas, Valencia de San Juan, Valencia de Alcántara, etc.) o Vivar del Cid (pueblo natal de Rodrigo Díaz, cerca de Burgos).

Pero la etimología de otros Cid de la Península Ibérica ya es más dudoso que se deba originariamente a ese personaje, aunque no se dude del origen árabe del

(14) M. DE EPALZA: «El Cid= El León...», p. 75. 
término, la voz sayyid, pronunciada coloquialmente síd (15). Hay otros probables derivados de sayyid, que Asin hace derivar de Zaid, pero no se va a entrar aqui en ese tema (16). Nos limitaremos al caso del topónimo alicantino Sierra del Cid y quizás al castellonense Villanueva del Cid. Permiten comprender ciertos mecanismos de creación de topónimos árabes (mejor dicho, "de origen árabe» o «arabismos») en el momento de la conquista cristiana, en el siglo XIII valenciano.

La Sierra del Cid («Serra del Cit» o «Serra del Cid», en documentación del siglo XVI, en catalán (17)) ha originado diversos topónimos a su alrededor: municipio de Monforte del Cid, pico Silla del Cid o Peña del Cid, Barranco del Cid, Planos o Plans del Cid, Embalse del Cid (18). La etimología más conocida es la referida al Cid Campeador $y$ ha originado numerosas leyendas bélicas en la comarca (19).

Pero algunos investigadores han sido reticentes a ese origen cidiano del nombre. Asin se limitó a señalar su étimo "sáyyid» (señor) (20). Navarro y Blasco le siguen, insinuando que su «señorio» le vendria a la Sierra por su posición prominente en el valle del río Vinalopó (21). El biólogo Climent, en un afán por tomar distancias del tradicional Cid, presentó la hipótesis de que el monte tomaría su nombre del pájaro «sit» (22). Finalmente, María Jesús Rubiera y yo presentamos la hipótesis de que se trataría de un topónimo «de reconquista», referente al «señor» precedente a la conquista cristiana, el sáyyid o príncipe-gobernador Abu-Zaid, último gobernador almohade y penúltimo soberano de Valencia y su región, en el siglo XIII (23). Es esta hi-

(15) Ver M. ASIN PALACIOS: Contribución a la toponimia árabe de España, Madrid-Granada, 1944, 2. ed. Lo atribuye al titulo o nombre de Rodrigo en los casos de Iglesuela del Cid (Teruel) ( Villafranca del Cid (Castellón) («nombre propio de persona: El Cid Campeador», p. 140), pero sólo menciona el étimo árabe en Sierra del Cid (Alicante) («señor», p. 103) y en los derivados de Villacid o Villazid (Coruña y Valladolid) ("señor" o "Sayyid", nombre propio de persona, p. 140), Benezid (Almeria) y Benesit (Alicante) ("Banu Sayyid", nombre de familia", pp. 86 y 92), Benexid (Maliorca) ("Banî Sayyidi", nombre de familia", p. 96).

(16) Hace venir del antropónimo Zayd a los topónimos Aceite (lbiza), Beceite (Teruel), Binaced (Huesca), Binaceite (Teruel), Calaceite (Teruel), Buceit (Cuenca), Venazaire o Benazaire (Badajoz), Villaceid y Villacete (León), Vinaceite (Teruel), Zaidin (Huesca), (o.C., pp. 42, 83, 94, 96, 136, 139, 142 y 144). Cada uno de estos topónimos requeriria un estudio promenorizado, a partir de las grafías antiguas y del estudio regionalizado y periodizado de los dialectos romances hispánicos.

(17) Ver C. NAVARRO I BELMONTE - M.C. BLASCO GARCIA: «Toponimia rural musulmana de la Vall de Novelda (1554-1609)», Xé. Col.loqui General de la Societat d'Onomàstica 1er. D'Onomástica Valenciana, Valencia, 1986, p. 453.

(18) Se encuentran en los términos municipales de Petrer, Novelda, Monforte del Cid y Agost. Curiosamente no están recogidos en J.L. ROMÁN DEL. CERRO - M. DE EPALZA: Toponimia mayor y menor de la provincia de Alicante. Listado por municipios, Alicante, 1983, más que Pla o Llanos del Cid (Agost, pp. 17-18) y Silla del Cid (Petrer, p. 241), además del municipio de Monforte del Cid, evidentemente.

(19) Recogido de la prensa alicantina en M. DE EPALZA: «Topónims d'origen antroponimic àrab de temps de la conquesta (Cid, Busot, Benimassot, Massoda, Benissoda)", XIVé Colloqui General de la Societat d'Onomàstica. I/n d'Onomàstica Valenciana, Alicante, 1989, actas en prensa.

(20) O.c., p. 103

(21) Ver supra, nota 13

(22) D. CLIMENT I GINER: «Una revisió toponimica necessària: el Sit, que no el Cid», Canalobre, Alicante, 10, $1987,37-40$

(23) Ver M.J. RUBIERA - M. DE EPALZA: Los nombres árabes de Benidorm y su comarca, Alicante, 1985, 25-26. Para los procedimientos con finalidad catastral que originaron muchos topónimos de origen árabe en la conquista, ver M. DE EPALZA - M.J. RUBIERA: «Estat actual dels estudis de toponimia valenciana d'origen àrab», Xé. Col.loqui.., 420-426; M. DE EPALZA: "Precisiones sobre instituciones musulmanas de las Baleares", Les liles Orientals d'Al-Andalus. V Jornades d'Estudis Histórics Locals, Palma de Mallorca, 1987, 84-85, y, con más detenimiento, en M. DE EPALZA: «Topónims...». 
pótesis la que se va a desarrollar a continuación.

El punto de partida puede ser el topónimo Benisid o Benisit (partida rural en un monte sobre el pueblo de Relleu, provincia de Alicante), que parece un nombre de familia árabe, con significado de «os hijos de Sayyid», como indicó Asín Palacios, pero que en realidad sería etimológicamente un híbrido latín-árabe penna-as-sayyid, «a peña del señor».

Pero se puede precisar algo más quién era ese «señor», partiendo de la hipótesis, muy lógica, de que los antropónimos árabes que se encuentran en la toponimia son de los últimos propietarios musulmanes, salvo que se pueda justificar documentalmente el remontar el origen a una época anterior (25). Pues bien, para el sáyyid del Benisid de Relleu, así como para el sáyyid de la Sierra que separa el valle del Vinalopó de la Foia o depresión de Castalla, se puede identificar a un sáyyid muy conocido, el sáyyid por excelencia de mediados del siglo XIll valenciano, el sáyyid Abu-Zaid.

En la Valencia del régimen y dinastía almohades (1172-1229, en esta ciudad) la palabra o título sayyid, sin dejar de tener su valor general en árabe de «señor», designa a los príncipes de la familia gobernante califal, que asumen todos los cargos políticos y militares del Estado, especialmente el gobierno de las provincias de ese amplio imperio que fundara Abd-Al-Mumin ('Abd Al-Mu'min) (1130-1163), desde Valencia a Tripolí del Mágreb (26). El último sáyyid en Valencia fue Abu-Zaid, biznieto del fundador de la dinastía, que sucedió a un tío suyo, que a su vez había sucedido a su primo el sáyyid Abu-Abd-Allah Muhámmad Ibn-Abi-Hafs, padre de Abu-Zaid (27).

Abu-Zaid gobernó Valencia entre 1223 y 1229 como gobernador o wâlî, pero al final lo hizo como soberano prácticamente autónomo, por las luchas dinásticas que hacian inoperante el gobierno de la corte califal de Marraquech en las lejanas provincias de Al-Andalus. Por eso se titulará rey, en la documentación cristiana. Fue derrocado por un príncipe local, de la precedente dinastía de los Ibn-Mardanix, que habian gobernado la región de Murcia-Valencia entre las dinastias de los almorávides y la de los almohades, de Marraquech (1144-1172). Este rey Abu-Jumail Zayyán lbn-Mardanix fue el último soberano musulmán valenciano (1229-1238), para serlo luego de Denia, Xátiva, Murcia y Alicante (hasta 1241) y refugiarse finalmente en Túnez, donde murió (1259/1260) (28).

(24) Ver M. ASIN PALACIOS: 0.C.; p. 92. La argumentación para justificar una etimología de sfalso Benim y el hibridismo latin-árabe, en RUBIERA - EPALZA: supra, nota 19

(25) Ver supra, nota 19 y M. DE EPALZA: «Los beréberes y la arabización del País Valenciano», Quaclerns de Filologia. Miscel lania Sanchis Guarner, Valencia, 1, 1984, 91-100, sobre las limitaciones de la toponimia de época cristiana de las dinastias beréberes de almorávides y almohades, del XII-XIII.

(26) Sobre los sáyyid almonades, ver A. HUiCl MIRANDA: Historia politica del imperio Almohade, Tetuán, 1956-1957, vol. II, 613-630

(27) Sobre este personaje, objeto de muchos estudios basados en relativamente poca documentación, árabe $c$ cristiana, ver los trabajos de conjunto de E. MOLINA LOPEZ: Ceyt Abu Ceyt. Novedades y rectificaciones. Almería, 1977; M.C. BARCELÓ TORRES: «El Sayyid Abû Zayd: príncipe musulmán, señor cristiano», Awrâq. Madrid, 3,1980,101-109, y de entre los muchos trabajos del profesor americano que se refieren a él. R.1 BLRNS: «Príncipe almohade y converso mudéjar; nueva documentación sobre Abû Zayd», Sharq Al-Andalus. Estudios Arabes, Alicante, 4, 1987, 109-122

(28) Para la compleja cronología de los acontecimientos políticos en la región, ver E. MOLINA LÓPEZ: «Por una cronologia histórica sobre Sarq Al-Andalus", Sharq Al-Andalus. Estudios Arabes, Alicante, 3, 1986, 39-55. 
Mientras tanto el sáyyid Abu-Zaid se aliaba con el rey de Aragón Jaime I, cooperaba con él en la conquista del Reino de Valencia y recibia hasta su muerte (hacia 1263) numerosos favores reales, para él y para los suyos, una amplia parentela fruto de su alianza con nobles familias aragonesas. Se hizo cristiano y usó el nombre y título de Vicente de Belvís, sin dejar de utilizar su título y nombre árabe, por los que era conocido. Aparece, en efecto, en la documentación cristiana, como Zeit Abu Zeit, Aceyt Aboseyt, Ceyt Abuceyt o simplemente Azeit, con el articulo asimilado de assayyid, «el sáyyid» por excelencia (29). FIG. 2:

Sus posesiones conocidas se situaban en cuatro regiones bien delimitadas, implicadas con las de sus parientes aragoneses y en régimen diverso de señorio o tenencia:

1. En el Alto Palancia y Alto Mijares castellonenese (zona de Belvís, Arenós, Segorb y Xérica).

2. En la zona de Torre Buceit, en Cuenca, dependiente de la Orden de Santiago.

3. En la zona de Alpont.

4. En las zonas alicantinas (entonces, frontera meridional de los territorios de la Corona de Aragón) de Orxeta y Finestrat (montes de Villajoyosa) y de Castalla.

Estas últimas posesiones corresponden al norte de la línea fronteriza de la Corona de Aragón con la de Castilla, en un corredor donde Aragón ocupaba las zonas montañosas, entre las fortalezas de Polop y Xixona (para Masanes, Orxeta, Relleu, Torres y Ana-Finestrat) y entre Xixona y Biar (para Castalla, Ibi, Tibi y Onil), mientras que la jurisdicción castellana se ejercia en la llanura alicantino-murciana.

Es precisamente en estos dos corredores montañosos donde se encuentran los dos topónimos mencionados relacionados con el nombre del Cid: Benisid, en Relleu (cerca de Orxeta, propiedad o tenencia del sáyyid Abu-Zaid), y Sierra del Cid (cerca de Castalla, castillo que gobernaba sus posesiones de Ibi, Tibi y Onil, en la misma Foia).

Por sus posesiones conquenses de Torrebuceit se sabe que el sáyyid daba nombre a sus tierras. Posiblemente fueron suyas otras posesiones que han dejado topónimos con su nombre o su titulo, en Benissa (La Marina Alta, provincia de Alicante) (30), en la zona de Orihuela (31), en Banyoles (Alt Vinalopó, prov. Alicante (32)) y

(29) Ver E. MOLINA LÓPEZ: Ceyt..., p. 20, y R.I. BURNS: 0.c. p. 112.

(30) Buceyt, según opina M.J. RUBIERA MATA, en el I Congrés d'História de La Marina Alta, en prensa.

(31) Aceyt, Açeyt, Azeyt, según M.T. FERRER I MALLOL: «Toponímia medieval d'Oriola», Miscel.lània d'Homenatge a Enric Moreu-Rey, Montserrat, 1988, II, 202-203, y C. BARCELÓ TORRES: Toponimia arábica del Pais Valencià. Alqueries i castells, Valencia, 1983, p. 243.

(32) Benasaiz, Benassai, Benassait, según J.L. ROMÁN DEL CERRO - M. DE EPALZA: o.c., p. 59, y V. BEREN GUER I MICO: «Aproximació a l'estudi dels malnoms de Banyeres de Mariola (L'Alcoià)», Societat d'Onomàs tica. Butlleti Interior, Barcelona, XXII, decembre, 1985, p. 53. 


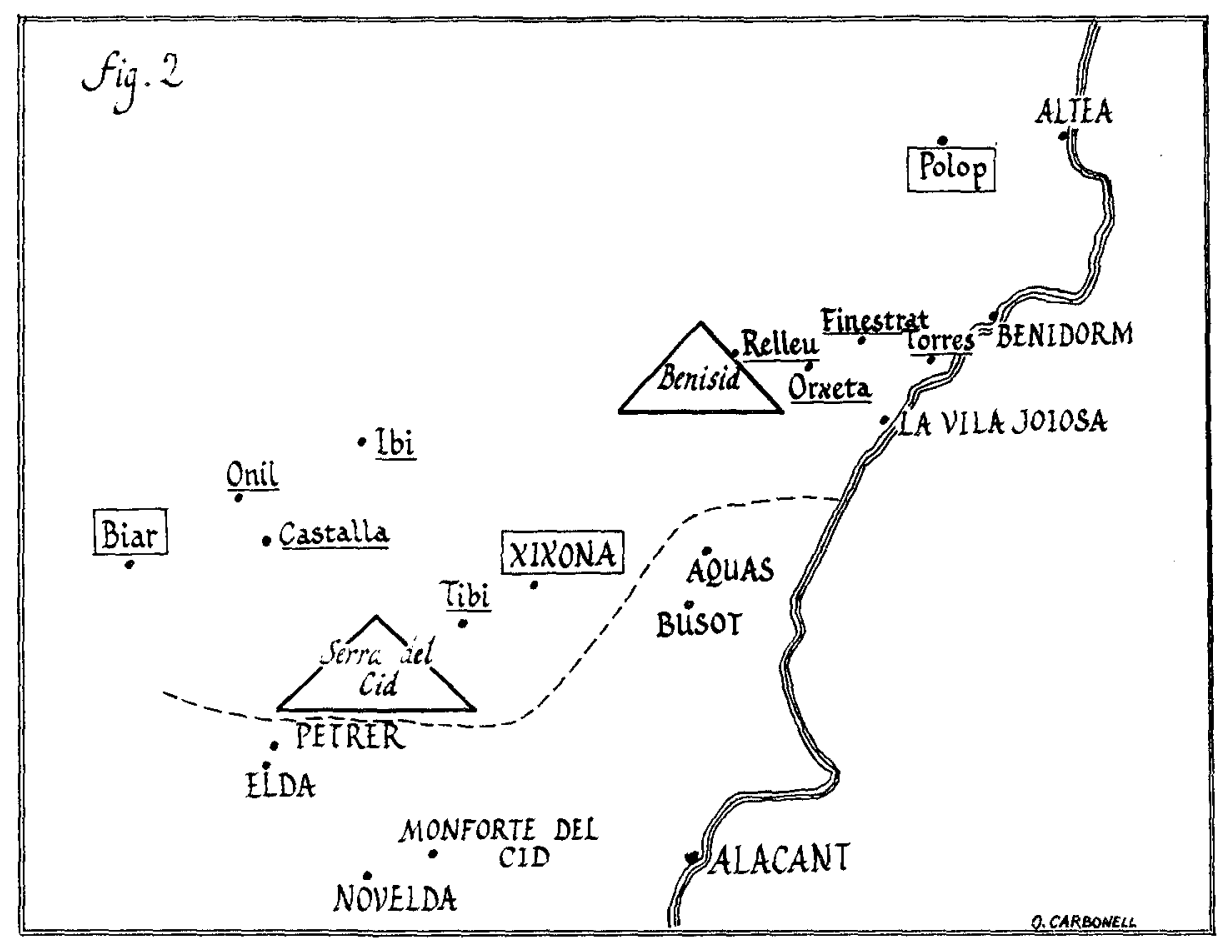

Topónimos y propiedades relacionados con Sáyyid Abu-Zaid 
Albaida (prov. de Valencia (33)), pero estos topónimos, al no estar documentada su relación con el sáyyid Abu-Zaid más que por si mismos, no dan la seguridad de los referidos antes, relacionados con propiedades documentadas de ese personaje.

Todo este conjunto de convergencias probaría, en la medida en que pueden ser probados estos fenómenos lingüísticos y sociales de esa época, el origen antroponímico de este topónimo Cid, proveniente del sáyyid o sid, «señor» y/o «gobernador» de época almohade.

\section{Resumen o conclusión}

Con argumentos diversos y complementarios, especialmente filológicos, se ha podido presentar unas etimologías probablemente más antiguas y originales, referentes al antropónimo y al topónimo Cid, además del conocido arabismo sayyid, «señor»: El Cid, como antropónimo, vendria de síd, «león» y algunos Cid de la toponimia se referirian a unos «señor» o «propietario», especialmente al conocido sáyyid AbuZaid, príncipe-gobernador de Valencia y penúltimo soberano de dicha ciudad.

(33) La Seyt, según J. GIL - MASCARELL BOSCA - L. ORTIZ GARCIA - BUSTELO: "Toponimia d'Albaida en 1626", Xé Colloqui..., pp. 132-134. 